\title{
Expression profiling of non-small cell lung carcinoma identifies metastatic genotypes based on lymph node tumor burden
}

Chuong D. Hoang, MD, Jonathan D'Cunha, MD, PhD, ${ }^{\text {a }}$ Sherif H. Tawfic, MD, PhD, ${ }^{\text {b }}$ Angelika C. Gruessner, PhD, ${ }^{\mathrm{c}}$ Robert A. Kratzke, MD, ${ }^{d}$ and Michael A. Maddaus, MD $^{\mathrm{a}}$

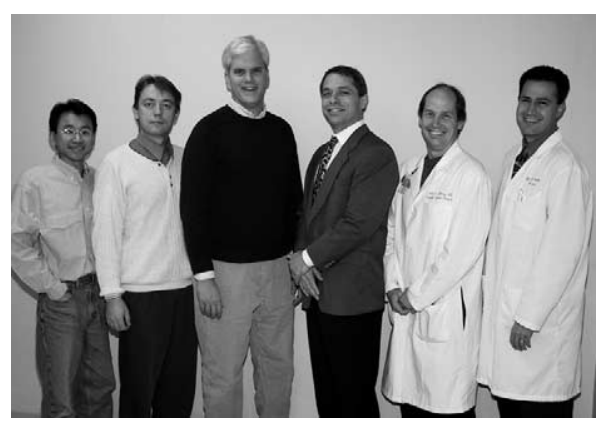

Hoang, Dudek, Kratzke, Maddaus, Dahlberg, D’Cunha (left to right).

Objective: This study hypothesized that non-small cell lung carcinoma cells from primary tumors isolated by laser capture microdissection would exhibit gene expression profiles associated with graded lymph node metastatic cell burden.

Methods: Non-small cell lung carcinoma tumors $(n=15)$ were classified on the basis of nodal metastatic cell burden by 2 methods, obtaining 3 groups: no metastasis, micrometastasis, and overt metastasis. We then performed microarray analysis on microdissected primary tumor cells and identified gene expression profiles associated with graded nodal tumor burden using a correlationbased selection algorithm coupled with cross-validation analysis. Hierarchical clustering showed the regrouping of tumor specimens; the classification inference was assessed with Fisher's exact test. We verified data for certain genes by using another independent assay.

From the Division of Cardiovascular and Thoracic Surgery, ${ }^{\text {a }}$ Department of Patholo$\mathrm{gy},{ }^{\mathrm{b}}$ and Division of Surgical Sciences, Statistics, Department of Surgery, ${ }^{\mathrm{c}}$ University of Minnesota Medical School, Minneapolis, Minn, and Division of Hematology, Oncology, and Transplant, ${ }^{\mathrm{d}}$ University of Minnesota Medical School, and the Research Service, Veterans Affairs Medical Center, Minneapolis, Minn.

C.D.H. is supported by grants from the Lillehei Heart Institute, the Veterans of Foreign Wars/Ladies Auxiliary Cancer Research Center Endowment Fund, the Cancer and Leukemia Group B Foundation Clinical Research Award and Fellowship, and a training program grant from the National Institutes of Health (T32HL07062) awarded to the Division of Hematology, Oncology, and Transplant, Univeristy of Minnesota.

Received for publication May 2, 2003; revisions received Oct 30, 2003; accepted for publication Nov 10, 2003

Address for reprints: Michael A. Maddaus, MD, Section of General Thoracic Surgery, Division of Cardiovascular and Thoracic Surgery, MMC 207, 420 Delaware Street SE, Minneapolis, MN 55455 (E-mail: madda001@tc.umn.edu).

J Thorac Cardiovasc Surg 2004;127:1332-42 $0022-5223 / \$ 30.00$

Copyright $\odot 2004$ by The American Association for Thoracic Surgery

doi:10.1016/j.jtcvs.2003.11.060
Results: The 15 specimens clustered into 3 groups: cluster A predominated in specimens with overt nodal metastasis; cluster B had more specimens with nodal micrometastases; and cluster $\mathrm{C}$ included only specimens without nodal metastases. Cluster assignment was based on a validated 75 -gene discriminatory subset. Notably, genes not previously associated with positive non-small cell lung carcinoma lymph node status were encountered in the profiling analysis.

Conclusions: Microdissection, combined with microarray analysis, is a potentially powerful method to characterize the molecular profile of tumor cells. The 75-gene expression profiles representative of clusters A and B may define genotypes prone to metastasize. Overall, the 3 groups of tumor specimens clustered separately, suggesting that this approach may identify graded metastatic propensity. Further, genes singled out in clustering may yield insights into underlying metastatic mechanisms and may represent new therapeutic targets.

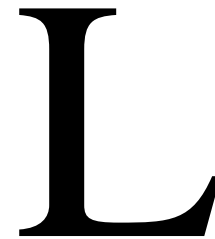

ung cancer remains the most common cause of cancer-related mortality in North America, accounting for 30\% of all cancer deaths, exceeding the next 4 cancers (breast, colon, prostate, and pancreas) combined. ${ }^{1}$ A critical, independent factor affecting the negative prognosis of patients with non-small cell lung carcinoma (NSCLC) is lymph node metastasis, a process with poorly defined molecular mechanisms. Nevertheless, the 5-year survival rate for patients with stage I lymph node-negative NSCLC is only $39 \%$ to $67 \% .^{2}$ The relatively high mortality rate of patients with stage I NSCLC is at least in part attributable to metastasis, often occult at the time of initial diagnosis. Occult metastatic tumor cells or micrometastases, routinely missed on histopathologic analysis, require immunohistochemical analysis or polymerase chain reaction (PCR)-based assays for detection. One study showed that the presence of such micrometastases in regional lymph nodes of patients with 
NSCLC was an independent risk factor associated with a reduced disease-free interval. ${ }^{3}$ In other solid tumor types, lymph node micrometastases correlated with primary tumor depth of penetration, lymphatic vessel invasion, microscopic venous invasion, and histologic stage. ${ }^{4,5}$ Taken together, this increasing body of evidence suggests that the presence of micrometastases in NSCLC lymph nodes is associated with a more biologically aggressive primary tumor. ${ }^{3,6}$ Currently, the basis of this important association is not well understood.

One investigative approach would be to identify molecular characteristics from the primary resected tumor that could predict the degree of lymph node micrometastatic cell burden. Doing so would be advantageous, potentially obviating the cumbersome logistics of lymph node sampling and of micrometastases detection. Microarray gene expression profiling is uniquely suited for molecular characterization: large numbers of genes can be simultaneously investigated, and the resulting gene expression patterns can then be correlated with certain clinical parameters. ${ }^{7}$ Using microarray technology to analyze lung carcinoma tissue, researchers have identified subgroups of tumors differentiated according to tumor type and histologic subclasses. ${ }^{8}$ Beer and colleagues ${ }^{9}$ extended this body of work by demonstrating that microarray gene expression profiles derived from tumor tissue could predict overall survival in patients with earlystage lung adenocarcinomas. Complementary to this ability is the need to identify patients at high risk for recurrent or metastatic disease. Recently, Kikuchi and coworkers ${ }^{10}$ reported on the feasibility of using gene expression profiling to predict gross, pathologic lymph node status in a subgroup of patients with NSCLC adenocarcinomas.

Because the cellular heterogeneity of whole tumor specimens may confound microarray analysis, we employed laser capture microdissection (LCM) ${ }^{11}$ to isolate pure cell populations for our molecular studies. Others have concluded that the gene expression signature derived from pure populations of tumor cells yields more precise, biologically meaningful information on specimens of interest. ${ }^{10,12}$ Thus, we hypothesized that pure populations of NSCLC cells would exhibit a gene expression pattern associated with the presence of not only overt metastatic cells but also, in particular, micrometastases in lymph nodes. This specific interest led us to select tumors with nodal micrometastases to be contrasted against 2 extremes: tumors without evidence (pathologic and molecular) of nodal involvement versus advanced-stage tumors. We isolated tumor cells from these 3 groups of tumors with graded lymph node metastatic cell burdens for subsequent gene expression profiling. In addition to analyzing the resulting gene expression patterns, we also investigated individual component genes for potential insights into novel metastatic mechanisms.

\section{Materials and Methods}

\section{Patients and Tumor Specimens}

All tumors and lymph nodes used in this study were obtained from a tumor tissue bank at our institution. Clinical outcome results from specimens used in this study were known only after all microarray experiments were performed and analyzed. Surgically resected specimens were collected under approval from the Institutional Review Boards at the University of Minnesota and the Minneapolis Veterans Affairs Medical Center. Patients gave written informed consent to have their tissues stored in a tumor tissue bank beforehand. None of the patients had a history of lung cancer or a concurrent malignancy, nor had they been exposed to any chemoradiotherapy. All lymph node specimens were bivalved: half were reserved for routine histopathologic analysis, and half were immediately snap-frozen in liquid nitrogen. Histopathologic testing verified that all surgical tumor specimens contained malignant cells. From stage I patients, only lymph nodes confirmed as pathologically negative (N0) were used. Some patients were upstaged to stage IIIa after histopathologic testing; they were also identified for our study. Based on previous protocols, ${ }^{10,13}$ we used pooled, noncancerous, male adult human lung total RNA isolated and purified from tissue (Stratagene, La Jolla, Calif) as a reference "normal" sample for each microarray experiment.

\section{Determination of Lymph Node Micrometastatic Cell Burden}

Our group previously described in detail a carcinoembryonic (CEA)-based real-time reverse transcriptase-PCR (QRT-PCR) assay to quantitatively estimate lymph node micrometastatic cell burden. ${ }^{14}$ A lymph node station was considered positive by QRTPCR for CEA if it had $>1000$ micrometastatic cells (sensitivity of the assay). Hematoxylin and eosin (H\&E) status of lymph nodes was determined by surgical pathologic analysis according to standard criteria. With each method, we identified results as positive $(+)$ or negative $(-)$. Patients with 5-year follow-up were identified from our tissue bank, and their lymph nodes were tested until we reached the following tumor specimen numbers: $5 \mathrm{H} \& \mathrm{E}-/(\mathrm{QRT}-$ PCR $)-; 5$ H\&E-/(QRT-PCR $)+$ (micrometastases); and 5 $\mathrm{H} \& \mathrm{E}+$.

\section{Laser Capture Microdissection and RNA Processing}

Tumor specimen sections were prepared by standard pathologic techniques, then stained with $\mathrm{H} \& \mathrm{E}$ just before microdissection. The PixCell II LCM System (Arcturus Engineering, Mountain View, Calif) was used according to the manufacturer's protocols. A board-certified surgical pathologist (S.H.T.) assisted in the differentiation of malignant cells. Areas of tumor necrosis were identified and excluded from harvesting. In all, 3000 to 5000 cells were laser captured for experiments. Total RNA was extracted from LCM tumor samples using the PicoPure RNA isolation kit (Arcturus Engineering), as outlined by the manufacturer. Adequate RNA starting material was generated using a T7 RNA polymerasecatalyzed linear amplification method. ${ }^{15}$ The RiboAmp RNA amplification kit (Arcturus Engineering) was used in 2 successive rounds on all LCM-isolated RNA samples, as outlined by the manufacturer. RNA purity was determined by spectrophotometry, and integrity was verified on ethidium bromide-stained $2 \%$ agarose-formaldehyde gels. To avoid any potential cDNA labeling bias 
in the microarray step, we also amplified the reference nonmalignant lung total RNA in an identical manner.

\section{cDNA Microarrays}

Microarray experiments were performed, with minor modifications, using the MicroMax Human 2400-gene cDNA Microarray System 1.1-TSA (Perkin Elmer LifeSciences, Boston, Mass). Briefly, for every microarray, $1 \mu \mathrm{g}$ of amplified RNA from each LCM tumor sample and the nonmalignant lung reference sample was reverse-transcribed to target cDNA by adding 280 pmol random hexamers (Promega, Madison, Wis) to the synthesis reaction. We calculated the mean coefficient of variation (CV) among microarray experiments $(\mathrm{n}=3)$ at $<31 \%$, suggesting adequate reproducibility (and consistent with the manufacturer's parameters).

\section{Microarray Analysis}

Each gene was represented on a microarray in duplicate, so that a corresponding raw expression ratio was defined as the mean signal intensity of tumor sample:reference sample replicates ( $\pm 2 \mathrm{SD}$ ). The raw expression ratios for each gene were median-centered normalized $^{16}$ to facilitate comparison of relative gene expression levels. To identify a set of genes that could distinguish between tumor samples on the basis of lymph node tumor burden, we applied the separate groups, K-ordered groups filtering algorithm (Expressionist v3.1, GeneData, San Francisco, Calif) to our entire data set. This algorithm consists of combining rank-ordering tests with a Pearson correlation coefficient to identify certain genes with expression ratios that are consistent within and distinct between defined groups. We selected a Pearson coefficient of 0.9 and specified 3 groups according to our criteria for lymph node status. This process identified a subset of genes that could be used to classify the tumor cell samples into 3 separate groups of nodal tumor burden. To determine the accuracy of our selection algorithm in finding a discriminatory gene subset, we performed a leave-one-out cross-validation analysis ${ }^{9}$ and calculated the error rate. After validating the gene subset, we used it in 2-dimensional hierarchical cluster analysis ${ }^{17}$ to visualize the subsequent clustering of tumor samples.

In another approach, we also selected genes that were greatly overexpressed or underexpressed by tumor cells in comparison with nonmalignant lung tissue by using a published filtering algorithm, ${ }^{13}$ with modifications. Briefly, the 50th percentile of all measurements per tumor sample was used as a positive control for each gene; the signal intensity of every gene was divided by this synthetic positive control. The bottom 10th percentile of measurements was used as a test for background subtraction. The measurement for each gene was then divided by the corresponding signal intensity of the nonmalignant lung sample. The threshold value used to define significant relative expression changes was set at 3.0 for overexpression and 0.30 for underexpression on the basis of the experimental variability in our data $(\mathrm{CV}<31 \%)$ and of the manufacturer's established performance criteria. Data filtering with this algorithm identified genes overexpressed by at least threefold and underexpressed by at least $30 \%$ across all specimens and within subgroups.

\section{QRT-PCR}

To examine the reliability of our microarray data, we selected 3 overexpressed genes (pescadillo, Brk, OB-cadherin) and determined their relative expression in similar samples used for microarray analysis by QRT-PCR, according to our previous protocol. ${ }^{14}$ For each gene, as well as for an endogenous control gene $\beta$-glucuronidase (GUSB), we designed TaqMan probe and primer sets from the open reading frame by using Primer Express software v2.0 (Applied Biosystems, Foster City, Calif). Details of primerprobe sequences are included in Appendix 1. PCR products of the expected size for each gene were eluted from ethidium bromidestained $2 \%$ agarose gels; their identities were confirmed by sequence analysis.

Relative quantitation of gene transcripts was calculated by the comparative threshold cycle method. ${ }^{18}$ GUSB was used as an endogenous control for the normalization of sample loading because levels are consistent across diseased and nondiseased lung tissues. ${ }^{19}$ The calibrator was chosen to be the same reference sample (nonmalignant lung) used for microarrays to facilitate comparison between the different techniques. Relative, normalized quantitative gene expression levels were calculated for the 3 genes of interest among tumor specimens.

\section{Statistics}

Microarray analysis was performed on Expressionist Suite v3.1 software (GeneData). The separate groups, K-ordered groups test proceeded in 4 steps: transforming expression ratios to ranks, rank-ordering within defined groups, rank-ordering between groups, and calculating a Pearson correlation statistic. The leaveone-out cross-validation analysis determined the robustness of the classification method. A sample was withheld from the total number of tumor samples; the remaining samples were used to select a set of discriminatory genes, and class prediction was made on the withheld sample. This process was repeated for every sample so that a cumulative error rate could be calculated. Fisher's exact test was used to assess whether or not cluster membership was associated with physical and molecular characteristics of the tumor samples.

Additional analysis was performed on S-Plus 6.1 software (Insightful, Seattle, Wash). Kaplan-Meier curves were used to estimate cause-specific patient survival (time in months from surgery until death), as well as recurrence rates. The log-rank test was used to assess differences among clusters. Differences of gene expression results between microarray and QRT-PCR techniques were analyzed according to previously described methods. ${ }^{20}$ Briefly, the distribution of log-transformed expression ratios (tumor specimen:reference sample) for genes of interest was determined.

\section{Results}

\section{Tumor Specimens}

Characteristics of tumor specimens included in our analysis are detailed in Table 1. In all, 10 NSCLC tumor specimens were pathologic stage I ( 7 T1 N0 and 3 T2 N0) and 5 were stage IIIa (2 T1 N2 and 3 T2 N2). By histologic examination, 12 specimens were adenocarcinomas; 3 were squamous cell carcinomas. We considered that this mixture of 
TABLE 1. Molecular and pathologic characteristics of NSCLC tumors

\begin{tabular}{|c|c|c|c|}
\hline Specimens & Histology & T status & Lymph node status \\
\hline P1 & AdenoCa & $\mathrm{T} 1$ & $\mathrm{H} \& \mathrm{E}-/(\mathrm{QRT}-\mathrm{PCR})+$ \\
\hline P2 & AdenoCa & T1 & $\mathrm{H} \& \mathrm{E}-/(\mathrm{QRT}-\mathrm{PCR})+$ \\
\hline P3 & AdenoCa & T1 & $\mathrm{H} \& \mathrm{E}-/(\mathrm{QRT}-\mathrm{PCR})-$ \\
\hline P4 & AdenoCa & T1 & $\mathrm{H} \& \mathrm{E}+$ \\
\hline P5 & SO & $\mathrm{T} 2$ & $\mathrm{H} \& \mathrm{E}+$ \\
\hline P6 & AdenoCa & $\mathrm{T} 1$ & $\mathrm{H} \& \mathrm{E}+$ \\
\hline P7 & SO & $\mathrm{T} 2$ & $\mathrm{H} \& \mathrm{E}+$ \\
\hline P8 & AdenoCa & $\mathrm{T} 2$ & $\mathrm{H} \& \mathrm{E}-/(\mathrm{QRT}-\mathrm{PCR})+$ \\
\hline P9 & AdenoCa & $\mathrm{T} 1$ & $\mathrm{H} \& \mathrm{E}-/(\mathrm{QRT}-\mathrm{PCR})+$ \\
\hline P10 & AdenoCa & $\mathrm{T} 2$ & $\mathrm{H} \& \mathrm{E}-/(\mathrm{QRT}-\mathrm{PCR})+$ \\
\hline P11 & AdenoCa & $\mathrm{T} 1$ & $\mathrm{H} \& \mathrm{E}-/(\mathrm{QRT}-\mathrm{PCR})-$ \\
\hline P12 & AdenoCa & $\mathrm{T} 2$ & $\mathrm{H} \& \mathrm{E}+$ \\
\hline P13 & AdenoCa & $\mathrm{T} 1$ & $\mathrm{H} \& \mathrm{E}-/(\mathrm{QRT}-\mathrm{PCR})-$ \\
\hline P14 & AdenoCa & T1 & $\mathrm{H} \& \mathrm{E}-/(\mathrm{QRT}-\mathrm{PCR})-$ \\
\hline P15 & SO & $\mathrm{T} 2$ & $\mathrm{H} \& \mathrm{E}-/(\mathrm{QRT}-\mathrm{PCR})-$ \\
\hline
\end{tabular}

NSCLC, Non-small cell lung carcinoma; AdenoCa, adenocarcinoma; SQ, squamous; $T$, according to International TNM staging system; $H \& E$, hematoxylin and eosin; QRT-PCR, real-time reverse transcriptase-polymerase chain reaction.

Specimens P1 to P15 correspond to Figure 1.

histologic types would aid in discovering gene profiles representative of NSCLC nodal metastasis overall because it is unknown whether or not different NSCLC types metastasize via unique mechanisms (and genes).

We tested lymph nodes (4 to 7 nodes per tumor; 1 lymph node per station) from the 10 stage I specimens to quantitatively estimate micrometastatic cell burden. A total of 53 lymph nodes were analyzed, 14 (26\%) of which were positive for CEA mRNA per our previous criteria (see Methods). These 14 lymph nodes were distributed among 5 of 10 stage I tumor specimens: 2 positive lymph nodes each in specimens P8-9, 3 positive lymph nodes each in specimens $\mathrm{P} 1$ and P10, and 4 positive lymph nodes in specimen P2. An estimate of lymph node micrometastatic cell burden within this 5-tumor specimen group averaged $4.0 \times 10^{4} \pm 2.3 \times 10^{4}$ (SD) CEA-positive cells per lymph node station. This process subdivided the stage I tumor specimens into 2 groups: 5 $\mathrm{H} \& \mathrm{E}-/(\mathrm{QRT}-\mathrm{PCR})-$ and $5 \mathrm{H} \& \mathrm{E}-/(\mathrm{QRT}-\mathrm{PCR})+$. To ensure that these QRT-PCR results were valid, we tested both the primary tumors $(\mathrm{n}=15)$ and H\&E+ lymph nodes $(\mathrm{n}=9)$ from the stage III tumor specimens. Correspondingly high CEA-positive cell numbers were observed in $12(80 \%)$ primary tumors and in 8 (89\%) lymph nodes.

\section{Hierarchical Cluster Analysis}

On average, 300 to 500 genes were excluded from downstream analysis, per the previously discussed criteria, after data normalization across these microarrays. The separate groups, K-ordered groups test was performed with an average of 2000 remaining genes from each microarray experiment per the 3 tumor groups defined above. This analysis identified a subset of 75 genes with significant differential expression patterns between the 3 defined tumor groups (Appendix 2). In other words, these genes displayed marked expression value changes from 1 tumor group to another, thereby facilitating tumor class discrimination. We coupled this gene-filtering method with a cross-validation analysis, calculating an error rate of $7 \%$. The members of this 75 -gene subset were diverse and encoded for molecules with various functions such as signal transduction, cellular structural components, transcription factors, cellular growth, adhesion, and trafficking.

We employed this validated 75-gene subset in 2-dimensional hierarchical clustering (Figure 1, A). We could not identify a clear pattern of segregation in the clustering when we examined each tumor by $\mathrm{T}$ status and histologic features $(P>.05)$ as expected (Table 1). However, cluster analysis discriminated between tumor specimens according to graded lymph node metastatic cell burden. Three distinct tumor clusters were identified: cluster A predominated in tumor specimens with $\mathrm{H} \& \mathrm{E}+$ lymph nodes; cluster B had more specimens with lymph node micrometastases; and cluster $\mathrm{C}$ had only specimens without any lymph node metastases (Figure 1, B). A significant association between cluster membership and the 3 groups of lymph node tumor burden was not discernible $(P=.13)$, but this result was not entirely unexpected given the small sample size. Nevertheless, the $P$ value trended in the appropriate direction toward statistical significance, warranting the addition of more study specimens. The number of tumor specimens with any degree of nodal metastasis decreased in a graded fashion across clusters A to $\mathrm{C}$ (Figure 1, B). The extent of lymph node metastasis also varied among clusters, as expected. Cluster A had a total of 14 tumor-positive lymph nodes [7 from stage III tumor specimens and 7 from $\mathrm{H} \& \mathrm{E}-/(\mathrm{QRT}-$ PCR $)+$ specimens]; cluster B, an intermediate number: a total of 9 tumor-positive lymph nodes [2 from a stage III specimen and 7 from $\mathrm{H} \& \mathrm{E}-/(\mathrm{QRT}-\mathrm{PCR})+$ specimens $]$. Cluster $\mathrm{C}$ was devoid of any nodal tumor involvement.

\section{Clinical Data}

Cause-specific 5-year survival (top) and NSCLC recurrence (bottom) data for the 15 patients are detailed in Table 2. The number of deaths secondary to NSCLC increased from cluster $\mathrm{C}$ (no deaths) to cluster A (3 deaths). The number of patients with NSCLC recurrence also increased from cluster $\mathrm{C}$ to cluster $\mathrm{A}$, whereas the median time to recurrence decreased by more than half from cluster B to cluster A. Kaplan-Meier curves reflected these trends (data not shown), but $P$ values did not reach statistical significance, as expected with this small sample size.

\section{Differentially Expressed NSCLC Genes}

Genes with significant overexpression and underexpression in common across tumor specimen groups were identified by 


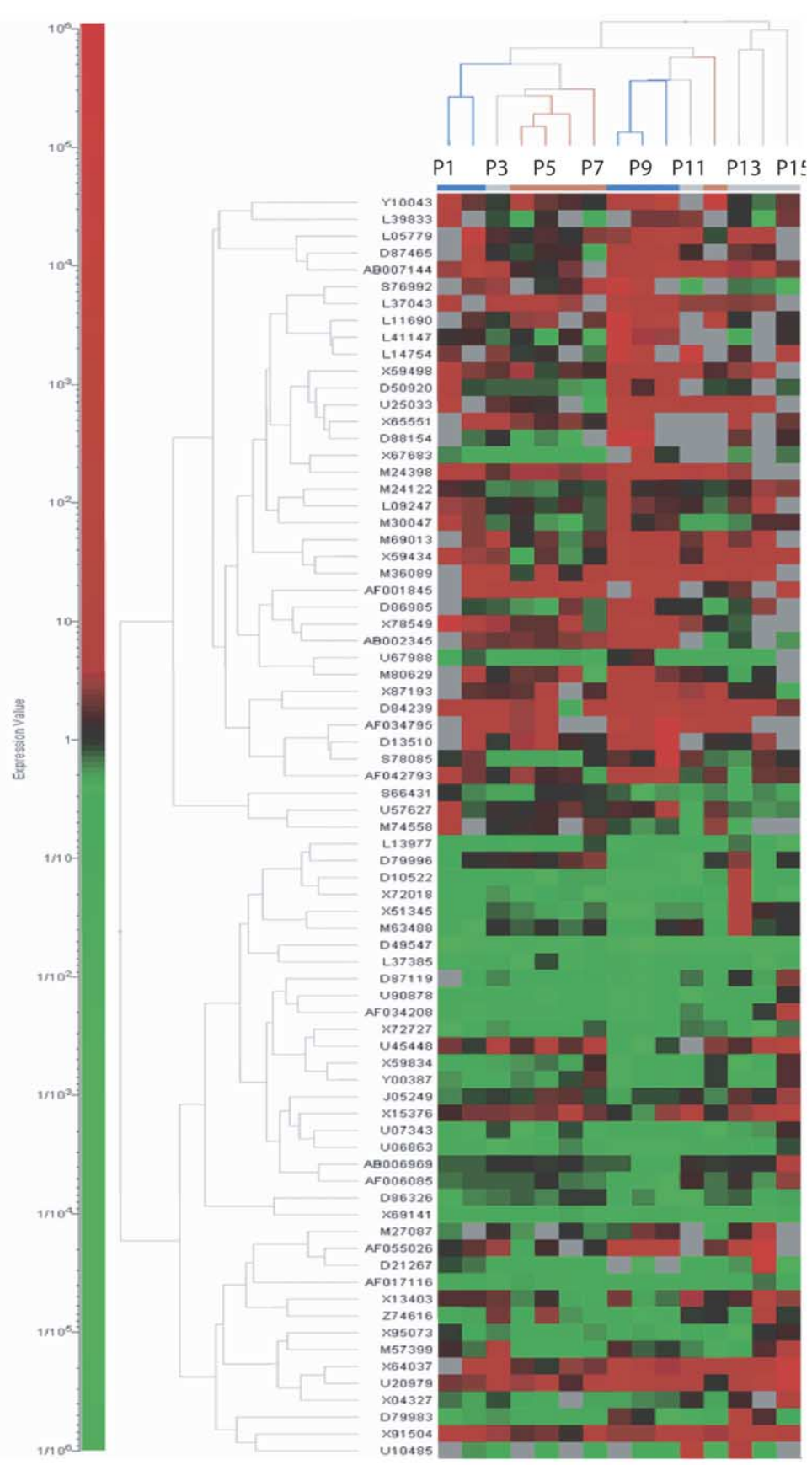

A

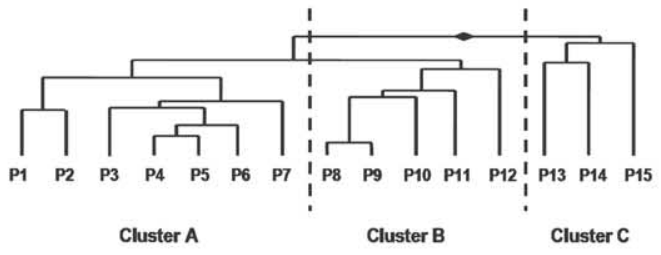

\begin{tabular}{lc|ccc} 
& \multicolumn{1}{c}{ LN Status } & Cluster A & Cluster B & Cluster C \\
\hline Stage I & H\&E-M(QPCR)- & 1 & 1 & 3 \\
Stage I & H\&E-M(OPCR)+ & 2 & 3 & 0 \\
Stage IIIA & H8E+ & 4 & 1 & 0 \\
\hline $\begin{array}{l}\text { Tumors with } \\
\text { positive LN }\end{array}$ & & $86 \%(6 / 7)$ & $80 \%(4 / 5)$ & $0 \%(0 / 3)$
\end{tabular}

B

Figure 1. Hierarchical cluster analysis. A, Two-dimensional hierarchical clustering of primary tumors per a 75-gene subset with differential expression across tumor specimen groups. Genes lie vertically and the GenBank accession numbers for all 75 genes are shown; specimens lie horizontally. Colors are mean, relative expression signal intensities for each gene. B, An enlarged view of the tumor specimen dendrogram from (A) along with a summary table of tumor specimen lymph node status.

systematic sorting. We found 109 genes in common to all specimens with greater than threefold overexpression relative to the reference, and conversely 45 genes with $<30 \%$ underexpression.
Specimen subgroup analysis identified genes as follows: H\&E-/(QRT-PCR) - , 157 over- and 242 underexpressed; H\&E-/(QRT-PCR)+, 190 and 280; H\&E+, 150 and 200. 
Multiple genes not commonly associated with NSCLC were identified (Appendixes 2 and 3). The $C L 100$ gene was significantly underexpressed by an average of 0.087 . Both $V A V 2$ (14.5-fold) and Brk (7.8-fold) were overexpressed in the specimen group with nodal micrometastases and conversely had low expression levels in the other 2 specimen groups. As the focus of our study was to identify gene expression patterns associated with metastatic potential, subgroup analysis of significantly altered genes in specimens with nodal micrometastases may be revealing (Appendix 3). Relative overexpression in specimens of OB-cadherin mRNA was 43.8-fold; of pescadillo mRNA, 39.5-fold. Concurrently, nidogen transcripts were underexpressed at 0.121 in specimens with nodal micrometastases.

Comparison of our results to previous NSCLC microarray profiling studies showed qualitative similarity in certain genes. Notable overexpressed or underexpressed genes in common with the study by Heighway and colleagues ${ }^{21}$ included osteopontin, insulin-like growth factor binding protein 2, gastrin-releasing peptide, and CL100; in common with the study by Beer and coworkers, ${ }^{9}$ aldolase A, cathepsin, and protein tyrosine phosphatase; and in common with the study by Bhattacharjee and colleagues, ${ }^{8}$ high-mobility group protein and bullous pemphigoid antigen. General agreement between different microarray studies using independent lung carcinoma samples suggests that many of these genes are likely relevant to NSCLC.

\section{Verification of Microarray Data}

Using QRT-PCR, we validated microarray expression data for 3 overexpressed genes (Brk, pescadillo, and OB-cadherin). Overall, results for each gene were broadly consistent between the 2 different techniques; for each gene tested, the QRT-PCR-derived median expression ratio changed in the same direction of differential expression as previously identified by the microarray analysis. These data confirmed the reliability of our microarray strategy in identifying differentially expressed genes from tumor specimens with varying nodal metastatic cell burden.

\section{Discussion}

Clustering algorithms have revealed subtle, specific patterns of gene expression useful for molecular classification of various cancers. ${ }^{8}$ Our study demonstrated the feasibility of using expression profiling to differentiate for the presence of lymph node micrometastases within stage I tumors. Our work extends that of Kikuchi and colleagues ${ }^{10}$ : we examined the molecular profile of tumors with nodal micrometastases as compared with advanced stage III tumors. The Kikuchi study focused on microarray identification of overt nodal status in a subset of adenocarcinomas, not reporting the specific clinicopathologic details of the patient group. Thus, in their study, identifying expression profiles specific to early-stage NSCLC
TABLE 2. Clinical data

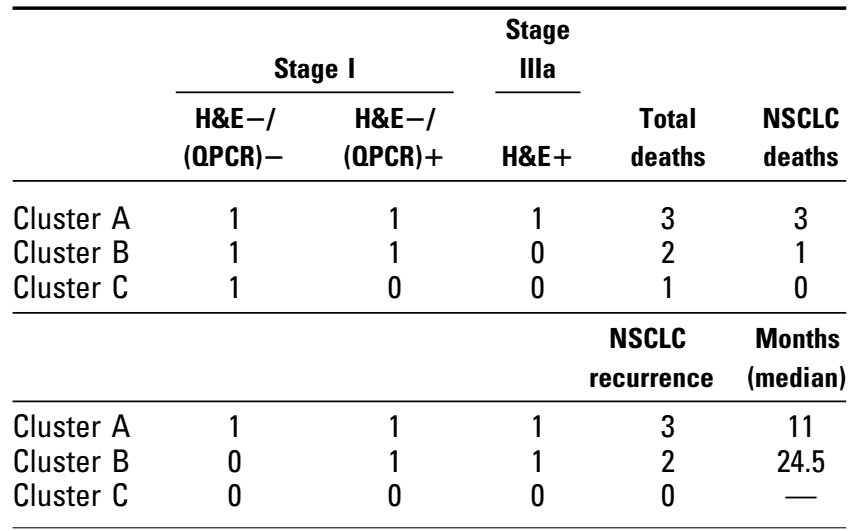

tumors (which are associated with a relatively poor patient survival rate and high recurrence rate) was difficult. Gene profiles of stage I NSCLC tumors associated with nodal micrometastatic cell burden may identify a high-risk subgroup prone to develop overt nodal metastases that could benefit from more aggressive initial therapy.

In our study, hierarchical clustering segregated LCM NSCLC specimens by graded lymph node metastatic burden (per CEA QRT-PCR), according to a 75-gene subset. The association, in the literature, of many of these subset genes with the pathogenesis of various epithelial-derived cancers lends indirect support for the validity of our 75-gene selection process. For example, $V A V 2$, a signal transduction gene, is associated with ovarian tumor progression. ${ }^{22}$ And $B r k$, a signaling transduction nonreceptor protein tyrosine kinase, is capable of potentiating the mitogenic response to epidermal growth factor in mammary epithelial cells ${ }^{23}$ and is overexpressed only in metastatic melanoma subtypes. ${ }^{24}$ Both $V A V 2$ and Brk were overexpressed in our group of tumor specimens with nodal micrometastases; thus, they may be potential tumor markers of early metastases.

In general, the 75-gene signature of cluster A may define a poor prognosis expression profile as cluster A contained mostly stage III tumor specimens. Also, we noted $1 \mathrm{H} \& \mathrm{E}-$ / (QRT-PCR) - tumor specimen (P3) that grouped into cluster A because it displayed an expression profile more similar to advanced-stage tumors. This observation proved to be biologically relevant: records indicated that patient P3 suffered a relapse at the initial resection site 7 months postoperatively, with a total survival time of only 11 months. Conversely, the gene signature of cluster $\mathrm{C}$ may define a subgroup of stage I lymph node-negative [H\&E-/(QRTPCR)-] patients with a favorable prognosis. Further, it may be significant that tumor specimens with lymph node micrometastases were distributed between clusters A and B, possibly consistent with the presence of novel micrometastatic molecular subgroups. Distinct micrometastatic subgroups may have significant implications for intermediate 
survival and cancer recurrence. Again, in our study, clinical data supported our conclusions. Of patients with nodal micrometastases, 2 of 3 (P8 and P10) in cluster B remain alive and disease-free; however, 1 of 2 (P2) in cluster A suffered a distant NSCLC relapse and survived only 15 months postoperatively.

We also identified significantly altered genes with potential functional links to NSCLC tumorigenesis (Appendixes 2 and 3). CL100, a homolog of mitogen-activated protein kinase phosphatase 1 , functions as a protein tyrosine phosphatase negatively regulating tyrosine kinase action. ${ }^{25}$ Loss of this gene, as displayed in all 15 of our specimens, may perpetuate tyrosine kinase-driven tumor growth, as evidenced in ovarian carcinoma cell lines. ${ }^{25}$ Among tumor specimens with nodal micrometastases, we identified a 3-gene set suggesting unrecognized mechanisms involved in NSCLC metastasis. OB-cadherin has been associated with more aggressive variants of breast or gastric cancers in which the gene product mediates formation of adherens junction complexes, enhancing the invasive ability of cancer cells. ${ }^{26}$ Pescadillo has been shown to be overexpressed in malignant astrocytes, colon, and breast carcinoma cell lines; it regulates the cell cycle in a manner permissive for tumor progression. ${ }^{27}$ Both of those genes were markedly overexpressed in this tumor subgroup; presumably, these have similar function. Interestingly, nidogen, a basement membrane-stabilizing molecule ${ }^{28}$ was significantly underexpressed in this subgroup of tumors with nodal micrometastases. Intuitively, we believe that basement membrane instability would be a prerequisite for metastasis. In a comparison with our other 2 tumor subgroups, we found a similar gene expression profile of these 3 genes in stage III tumors but not in stage I tumors with H\&E-/(QRT-PCR)lymph nodes. This finding suggests that some early-stage primary tumors with associated lymph node metastases may behave aggressively because they share a gene profile similar to advanced-stage primary tumors.

Admittedly, the sample sizes of our tumor specimen groups were too small to make broad, definitive generalizations on the lymph node status of NSCLC tumors based on the hierarchical cluster data. With a larger number of specimens, we would anticipate a more distinct and statistically significant delineation of cluster assignment correlating with quantitative lymph node micrometastatic cell burden. Nonetheless, our preliminary results support the concept of investigating this approach further for large-scale profiling of primary tumor cells to identify critical gene expression patterns.

Another limitation of our study was the use of different types of starting RNA source material: LCM tumor cells compared against pooled whole-lung tissue. Despite the potential to introduce experimental bias, Kikuchi and coworkers ${ }^{10}$ used the identical approach without obvious problems. Additionally, testing the predictive ability of the 75-gene subset on additional specimens would be an important next step toward prospectively classifying tumors by degree of lymph node metastatic cell burden. Currently, it is unknown whether the gene expression profiles defining tumor specimens in clusters $\mathrm{A}, \mathrm{B}$, and $\mathrm{C}$ have any prognostic impact, but our limited findings suggest differential survival among cluster groups.

In summary, LCM of primary tumors combined with microarray analysis identified a 75-gene expression profile that may identify early-stage NSCLC primary tumors that have increased metastatic propensity. Our approach differentiated between tumor specimens by graded levels of lymph node metastatic burden, identifying specimens with micrometastases separately from those with overt metastases. The individual genes defined by hierarchical clustering may suggest contributing pathogenic mechanisms in NSCLC and may represent new, early therapeutic targets. In future studies, it will be critical to test the ability of our 75-gene subset to predict nodal micrometastases to identify a subgroup of patients who may benefit from additional therapy. To refine this concept, it will also be important to correlate the primary tumor molecular signature with differing quantitative estimates of micrometastatic cell lymph node burden, possibly revealing molecular subgroups of tumors with micrometastases.

We are grateful to Suzanne Grindle (University of Minnesota Cancer Center, Bioinformatics Core) for technical assistance with microarray analysis software, as well as to Debra Herzan for timely and accurate assistance with clinical and pathologic data reported herein. We also thank Dr Mary Knatterud for expert editorial assistance.

\section{References}

1. Jemal A, Murray T, Samuels A, Ghafoor A, Ward E, Thun MJ. Cancer statistics, 2003. CA Cancer J Clin. 2003;53:5-26.

2. Lau CL, Harpole DH Jr. Lung neoplasms. In: Norton JA, editor. Surgery, basic science and clinical evidence. New York: Springer; 2000, p. 1189-216.

3. Maruyama R, Sugio K, Mitsudomi T, Saitoh G, Ishida T, Sugimachi $\mathrm{K}$. Relationship between early recurrence and micrometastases in the lymph nodes of patients with stage I non-small cell lung cancer. J Thorac Cardiovasc Surg. 1997;114:535-43.

4. Greenson JK, Isenhart CE, Rice R, Mojzisik C, Houchens D, Martin EW Jr. Identification of occult micrometastases in pericolic lymph nodes of Duke's B colorectal cancer patients using monoclonal antibodies against cytokeratin and CC49. Correlation with long-term survival. Cancer. 1994;73:563-9.

5. Ishida K, Katsuyama T, Sugiyama A, Kawasaki S. Immunohistochemical evaluation of lymph node micrometastases from gastric carcinomas. Cancer. 1997;79:1069-76.

6. Pantel K, Cote RJ, Fodstad O. Detection and clinical importance of micrometastatic disease. J Natl Cancer Inst. 1999;91:1113-24.

7. Liotta L, Petricoin E. Molecular profiling of human cancer. Nat Rev Genet. 2000;1:49-56.

8. Bhattacharjee A, Richards WG, Staunton J, Li C, Monti S, Vasa P, et al. Classification of human lung carcinomas by mRNA expression profiling reveals distinct adenocarcinoma subclasses. Proc Natl Acad Sci U S A. 2001;98:13790-5.

9. Beer DG, Kardia SLR, Huang CC, Giordano TJ, Levin AM, Misek 
DE, et al. Gene-expression profiles predict survival of patients with lung adenocarcinoma. Nat Med. 2002;8:816-24.

10. Kikuchi T, Daigo Y, Katagiri T, Tsunoda T, Okada K, Kakiuchi S, et al. Expression profiles of non-small cell lung cancers on cDNA microarrays: identification of genes for prediction of lymph-node metastasis and sensitivity to anti-cancer drugs. Oncogene. 2003;22:2192-205.

11. Bonner RF, Emmert-Buck M, Cole K, Pohida T, Chuaqui R, Goldstein $\mathrm{S}$, et al. Laser capture microdissection: molecular analysis of tissue. Science. 1997;278:1481-3.

12. Sugiyama Y, Sugiyama K, Hirai Y, Akiyama F, Hasumi K. Microdissection is essential for gene expression profiling of clinically resected cancer tissues. Am J Clin Pathol. 2002;117:109-16.

13. Sugita M, Geraci M, Gao B, Powell RL, Hirsch FR, Johnson G, et al. Combined use of oligonucleotide and tissue microarrays identifies cancer/testis antigens as biomarkers in lung carcinoma. Cancer Res. 2002;62:3971-9.

14. D'Cunha J, Corfits AL, Herndon JE 2nd, Kern JA, Kohman LJ, Patterson GA, et al. Molecular staging of lung cancer: real-time polymerase chain reaction estimation of lymph node micrometastatic tumor cell burden in stage I non-small cell lung cancer: preliminary results of Cancer and Leukemia Group B Trial 9761. J Thorac Cardiovasc Surg. 2002;123:484-91 (discussion 491).

15. Van Gelder RN, von Zastrow ME, Yool A, Dement WC, Barchas JD, Eberwine JH. Amplified RNA synthesized from limited quantities of heterogeneous cDNA. Proc Natl Acad Sci U S A. 1990;87:1663-7.

16. Quackenbush J. Computational analysis of microarray data. Nat Rev Genet. 2001;2:418-27.

17. Eisen MB, Spellman PT, Brown PO, Botstein D. Cluster analysis and display of genome-wide expression patterns. Proc Natl Acad Sci U S A. 1998;95:14863-8.

18. Livak KJ, Schmittgen TD. Analysis of relative gene expression data using real-time quantitative PCR and the 2(-Delta Delta C(T)) Method. Methods. 2001;25:402-8.

19. Gerard CJ, Andrejka LM, Macina RA. Mitochondrial ATP synthase 6 as an endogenous control in the quantitative RT-PCR analysis of clinical cancer samples. Mol Diagn. 2000;5:39-46.

20. Lin YM, Furukawa Y, Tsunoda T, Yue CT, Yang KC, Nakamura Y. Molecular diagnosis of colorectal tumors by expression profiles of 50 genes expressed differentially in adenomas and carcinomas. Oncogene. 2002;21:4120-8.

21. Heighway J, Knapp T, Boyce L, Brennand S, Field JK, Betticher DC, et al. Expression profiling of primary non-small cell lung cancer for target identification. Oncogene. 2002;21:7749-63.

22. Bourguignon LY, Zhu H, Zhou B, Diedrich F, Singleton PA, Hung
MC. Hyaluronan promotes CD44v3-Vav2 interaction with Grb2p185(HER2) and induces Rac1 and Ras signaling during ovarian tumor cell migration and growth. J Biol Chem. 2001;276:48679-92.

23. Barker KT, Jackson LE, Crompton MR. BRK tyrosine kinase expression in a high proportion of human breast carcinomas. Oncogene. 1997; 15:799-805.

24. Easty DJ, Mitchell PJ, Patel K, Florenes VA, Spritz RA, Bennett DC. Loss of expression of receptor tyrosine kinase family genes PTK7 and SEK in metastatic melanoma. Int J Cancer. 1997;71:1061-5.

25. Manzano RG, Montuenga LM, Dayton M, Dent P, Kinoshita I, Vicent S, et al. CL100 expression is down-regulated in advanced epithelial ovarian cancer and its re-expression decreases its malignant potential. Oncogene. 2002;21:4435-47.

26. Feltes CM, Kudo A, Blaschuk O, Byers SW. An alternatively spliced cadherin-11 enhances human breast cancer cell invasion. Cancer Res. 2002;62:6688-97.

27. Kinoshita Y, Jarell AD, Flaman JM, Foltz G, Schuster J, Sopher BL, et al. Pescadillo, a novel cell cycle regulatory protein abnormally expressed in malignant cells. $J$ Biol Chem. 2001;276:6656-65.

28. Miosge N, Holzhausen S, Zelent C, Sprysch P, Herken R. Nidogen-1 and nidogen-2 are found in basement membranes during human embryonic development. Histochem J. 2001;33:523-30.

\section{APPENDIX 1: Sequences of TaqMan primers and probes}

Brk forward primer 5-CCATGACCACAATATCCCCTACA-3, reverse 5-ACGTCGGATTTGGTGGAGTAA-3, and probe 5-TGGACGGCCCCTGAAGCGC-3; OB-cadherin forward primer 5-AAGACATCAAACCTGAGTATCAGTACATG-3, reverse 5-CATCGACATCCACGCTGTTG-3, and probe 5TAGACCTGGGCTCCGGCCAGC-3; pescadillo forward primer 5-CCATTCATCCTGGCTTTCCA-3, reverse 5-CCTACCCTCACCCCATCACA-3, and probe 5-CACAGTTGGACCCGTGATTCTCAGGG-3; and GUSB forward primer 5-CTCGGCAGAGACAACCAAAAA-3, reverse 5-GGTTTCATTGGCAATCTTCCA-3, and probe 5-TGCAGCGTTCCTTTTGCGAGAGAGAT-3

See Appendix 2 on page 1340. 
APPENDIX 2. Selected genes from the discriminatory 75-gene subset

\begin{tabular}{|c|c|c|c|c|c|}
\hline Discriminatory genes & Description & GenBank & $\begin{array}{l}\text { Stage I; H\&E-I } \\
\text { (ORT-PCR)- }\end{array}$ & $\begin{array}{l}\text { Stage I; H\&E-I } \\
\text { (ORT-PCR)+ }\end{array}$ & $\begin{array}{c}\text { Stage IIIA; } \\
\text { H\&E+ }\end{array}$ \\
\hline High-mobility group protein HMG & $\begin{array}{l}\text { Maintenance of nucleoprotein } \\
\text { complexes }\end{array}$ & Y10043 & $6.9( \pm 21.9)$ & $52.0( \pm 201.5)$ & $34.7( \pm 147.5)$ \\
\hline $\begin{array}{l}\text { (clone hKvBeta3) } \mathrm{K}+\text { channel beta } \\
\text { subunit }\end{array}$ & Ion channel & L39833 & $1.3( \pm 1.6)$ & $5.1( \pm 10.3)$ & $0.578( \pm 1.2)$ \\
\hline ZIP-kinase & Serine/threonine kinase & AB007144 & $6.7( \pm 12.1)$ & $29.5( \pm 66.4)$ & $2.4( \pm 3.3)$ \\
\hline VAV2, VAV oncogene homolog & Cell signaling & S76992 & $3.9( \pm 6.4)$ & $14.5( \pm 35.3)$ & $3.3( \pm 5.9)$ \\
\hline Neuronatin alpha & Neural development & U25033 & $7.2( \pm 14.4)$ & $29.1( \pm 41.5)$ & $2.0( \pm 4.3)$ \\
\hline $\begin{array}{l}\text { mki67a (short type) for antigen of } \\
\text { monoclonal antibody Ki-67 }\end{array}$ & Cell proliferation & X65551 & $3.4( \pm 3.1)$ & $70.8( \pm 154.4)$ & $1.9( \pm 1.0)$ \\
\hline Casein kinase I epsilon & DNA replication and repair & L37043 & $2.9( \pm 1.3)$ & $9.9( \pm 18.9)$ & $4.4( \pm 3.8)$ \\
\hline Bullous pemphigoid antigen (BPAG1) & Cytoskeletal protein & L11690 & $2.6( \pm 5.6)$ & $8.2( \pm 10.1)$ & $4.5( \pm 6.4)$ \\
\hline 5-HT6 serotonin receptor & Serotonin signaling & L41147 & $3.7( \pm 12.5)$ & $2.8( \pm 5.9)$ & $1.2( \pm 2.3)$ \\
\hline DNA-binding protein (SMBP2) & Immunoglobulin class switching & L14754 & $8.2( \pm 21.7)$ & $20.2( \pm 30.1)$ & $3.7( \pm 5.9)$ \\
\hline Transthyretin (Ttr) & Hormone transport & X59498 & $3.8( \pm 3.8)$ & $8.5( \pm 8.9)$ & $1.8( \pm 1.8)$ \\
\hline Villin-like protein & Cytoskeletal protein & D88154 & $2.1( \pm 3.2)$ & $30.6( \pm 64.5)$ & $4.8( \pm 18.8)$ \\
\hline Parathymosin & Cell proliferation & M24398 & $3.9( \pm 5.7)$ & $18.0( \pm 27.2)$ & $6.4( \pm 14.9)$ \\
\hline Gastrin-releasing peptide & Autocrine growth factor & K02054 & $1.4( \pm 1.2)$ & $0.729( \pm 0.620)$ & $11.8( \pm 10.3)$ \\
\hline $\begin{array}{l}\text { Receptor-type protein tyrosine } \\
\text { phosphatase }\end{array}$ & Protein dephosphorylation & L09247 & $3.8( \pm 9.3)$ & $2.9( \pm 2.9)$ & $1.0( \pm 0.860)$ \\
\hline $\begin{array}{l}\text { Guanine nucleotide-binding regulatory } \\
\text { protein }\end{array}$ & Intracellular signaling & M69013 & $6.7( \pm 11.8)$ & $10.2( \pm 20.9)$ & $2.0( \pm 3.1)$ \\
\hline Rhodanese (Rohu) & e substrate & X59434 & $3.7( \pm 4.0)$ & $8.8( \pm 10.3)$ & $1.5( \pm 3.0)$ \\
\hline DNA repair protein (XRCC1) & DNA re & M36089 & $13.9( \pm 11.5)$ & $19.0( \pm 5.1)$ & $5.9( \pm 12.9)$ \\
\hline Atrophin-1 related protein & Unknown & AF001845 & $7.2( \pm 15.3)$ & $26.4( \pm 14.4)$ & $13.4( \pm 19.2)$ \\
\hline Brk mRNA for tyrosine kinase & $\begin{array}{l}\text { Protein phosphorylation, } \\
\text { intracellular signaling } \\
\text { cascade }\end{array}$ & X78549 & $2.2( \pm 2.7)$ & $7.8( \pm 7.7)$ & $1.8( \pm 2.3)$ \\
\hline cdc2-related protein kinase (CHED) & Cell division regulation & M80629 & $1.0( \pm 0.860)$ & $6.0( \pm 8.3)$ & $1.8( \pm 2.8)$ \\
\hline IgG Fc binding protein & Immune regulation & D84239 & $5.1( \pm 3.6)$ & $10.1( \pm 10.8)$ & $3.4( \pm 3.8)$ \\
\hline Alpha 2 delta calcium channel subunit & Calcium homeostasis & AF042793 & $1.1( \pm 1.4)$ & $10.7( \pm 28.7)$ & $1.7( \pm 1.8)$ \\
\hline $\begin{array}{l}\text { Cell matrix adhesion regulator variant } \\
\text { (CMAR) }\end{array}$ & $\begin{array}{l}\text { Intracellular signaling, collagen } \\
\text { adhesion }\end{array}$ & AF034795 & $13.0( \pm 27.7)$ & $15.9( \pm 22.3)$ & $37.1( \pm 111.9)$ \\
\hline $\begin{array}{l}\text { Pancreatitis-associated protein (PAP) } \\
\text { homologous protein }\end{array}$ & Pancreas stress protein & D13510 & $2.3( \pm 4.5)$ & $3.3( \pm 2.6)$ & $2.4( \pm 4.5)$ \\
\hline $\begin{array}{l}\text { PDCD2, programmed cell death-2 } \\
\text { (Rp8 homolog) }\end{array}$ & Apoptosis regulation & S78085 & $0.592( \pm 0.680)$ & $0.671( \pm 0.446)$ & $0.519( \pm 0.557)$ \\
\hline $\begin{array}{l}\text { Retinoblastoma binding protein } 2 \text {, } \\
\text { RBP2 }\end{array}$ & $\begin{array}{l}\text { Nuclear receptor binding, } \\
\text { transcription }\end{array}$ & S66431 & $0.419( \pm 0.409)$ & $0.629( \pm 0.435)$ & $0.816( \pm 0.508)$ \\
\hline jun-B protein & Oncogene & $X 51345$ & 2.71 & $0.335( \pm 0.321)$ & $0.462( \pm 0.289)$ \\
\hline Heat shock protein 40 & Stress protein, & D49547 & $0.012( \pm 0.011)$ & $0.005( \pm 0.097)$ & $0.032( \pm 0.045)$ \\
\hline $\mathrm{P} 2 \times 1$ receptor & Cell signaling & U45448 & $7.3( \pm 16.1)$ & $0.905( \pm 1.5)$ & $3.0( \pm 2.9)$ \\
\hline GABA-A recept & Neurotransmission & X15376 & $6.7( \pm 16.4)$ & $1.5( \pm 1.6)$ & $3.8( \pm 8.3)$ \\
\hline $\begin{array}{l}\text { DNA mismatch repair protein homolog } \\
\text { (hMLH1) }\end{array}$ & DNA repair & U07343 & $0.681( \pm 0.831)$ & $0.265( \pm 0.103)$ & $0.473( \pm 0.362)$ \\
\hline Squalene synthase & & X69141 & $0.096( \pm 0.172)$ & $0.123( \pm 0.109)$ & $0.311( \pm 0.240)$ \\
\hline $\begin{array}{l}\text { Clone } 24444 \text { RaP2 interacting protein } 8 \\
\text { (RP1P8) }\end{array}$ & GTP binding regulation & AF055026 & $9.7( \pm 16.7)$ & $5.5( \pm 9.4)$ & $3.0( \pm 7.1)$ \\
\hline Octamer-binding protein, 0 ct- 1 & Transcription factor & $\mathrm{X} 13403$ & $5.0( \pm 11.8)$ & $1.3( \pm 1.3)$ & $0.698( \pm 0.872)$ \\
\hline Prepro-alpha2(1) collagen & Cytoskeletal protein & Z74616 & $1.9( \pm 3.6)$ & $0.224( \pm 0.343)$ & $0.939( \pm 2.0)$ \\
\hline Nerve growth factor (HBNF-1) & Neuronal growth & M57399 & $2.7( \pm 5.3)$ & $1.0( \pm 0.735)$ & $0.318( \pm 0.147)$ \\
\hline $\begin{array}{l}\text { RNA polymerase II associated protein, } \\
\text { RAP } 74\end{array}$ & Transcription initiation factor & X64037 & $6.2( \pm 8.4)$ & $6.2( \pm 9.9)$ & $2.1( \pm 3.3)$ \\
\hline $\begin{array}{l}\text { Chromatin assembly factor- } 1 \text { p150 } \\
\text { subunit }\end{array}$ & DNA replication & U20979 & $5.0( \pm 4.1)$ & $6.3( \pm 10.7)$ & $2.5( \pm 3.6)$ \\
\hline mRNA for KIAA0161 gene & Un & D79983 & $3.81 \pm$ & $0.820( \pm 1.3)$ & $0.228( \pm 0.130)$ \\
\hline ARP1 protein & Transcription factor & X91504 & $10.2( \pm 11.7)$ & $6.3( \pm 8.4)$ & $2.5( \pm 2.1)$ \\
\hline
\end{tabular}

$H \& E$, Hematoxylin and eosin; $Q R T-P C R$, real-time reverse transcriptase-polymerase chain reaction.

Numerical data are mean, relative expression ratios (fold or fraction changes) without units ( $\pm 2 \mathrm{SD}$ ). 
APPENDIX 3. Combined list of selected overexpressed or underexpressed genes and nodal micrometastasis-associated genes

\begin{tabular}{|c|c|c|c|c|c|}
\hline & Description & GenBank & $\begin{array}{l}\text { Stage I; H\&E-I } \\
\text { (ORT-PCR)- }\end{array}$ & $\begin{array}{l}\text { Stage I; H\&E-I } \\
\text { (ORT-PCR)+ }\end{array}$ & $\begin{array}{l}\text { Stage IIIA; } \\
\text { H\&E+ }\end{array}$ \\
\hline \multicolumn{6}{|l|}{ Overexpressed genes } \\
\hline $\begin{array}{l}\text { Epidermal growth factor receptor } \\
\text { substrate (eps15) }\end{array}$ & Cell growth regulation & U07707 & $28.1( \pm 56.3)$ & $67.6( \pm 96.1)$ & $9.6( \pm 10.3)$ \\
\hline Glucose transporter (HepG2) & Glucose metabolism & K03195 & $156.5( \pm 348.3)$ & $19.3( \pm 26.6)$ & $47.5( \pm 161.1)$ \\
\hline Integrase interactor 1 (Ini 1) & Nuclear factor & U04847 & $38.0( \pm 93.9)$ & $53.5( \pm 91.0)$ & $19.3( \pm 19.9)$ \\
\hline $\begin{array}{l}\text { Ninjurin1 (nerve injury-induced } \\
\text { protein) }\end{array}$ & Cell adhesion & U72661 & $19.3( \pm 34.7)$ & $140.1( \pm 483.6)$ & $10.0( \pm 9.7)$ \\
\hline Cathepsin D & Aspartic lysosomal proteinase & M11233 & $31.1( \pm 44.9)$ & $18.1( \pm 29.1)$ & $22.9( \pm 57.4)$ \\
\hline Frataxin (FRDA) & Mitochondrial iron metabolism & U43747 & $12.2( \pm 13.3)$ & $17.0( \pm 50.4)$ & $6.3( \pm 3.1)$ \\
\hline msg1-related gene 1 (mrg1) & Transcription factor & U65093 & $17.9( \pm 33.4)$ & $51.2( \pm 111.4)$ & $25.6( \pm 44.5)$ \\
\hline Triadin & Calcium homeostasis & U18985 & $8.5( \pm 10.1)$ & $39.8( \pm 46.6)$ & $21.1( \pm 55.8)$ \\
\hline RGP3 & G protein signaling & U27655 & $14.4( \pm 38.3)$ & $26.9( \pm 53.9)$ & $13.1( \pm 14.7)$ \\
\hline mRNA for osteopontin & Bone matrix protein & X13694 & $113.2( \pm 229.6)$ & $81.8( \pm 140.1)$ & $75.3( \pm 143.1)$ \\
\hline $\begin{array}{l}\text { Hepatocyte growth factor } \\
\text { activator inhibitor (HAI-1) }\end{array}$ & Protease inhibitor & AB000095 & & $167.3( \pm 429.8)$ & \\
\hline OB-cadherin-1 (cadherin-11) & Cellular adhesion & D21254 & & $43.8( \pm 106.7)$ & \\
\hline Calnexin & Protein trafficking & L18887 & & $13.1( \pm 16.4)$ & \\
\hline Creatine transporter & Protein transport, bioenergetics & L31409 & & $18.3( \pm 31.9)$ & \\
\hline $\begin{array}{l}\text { Insulin-like growth factor binding } \\
\text { protein-2 (IGFBP-2) }\end{array}$ & IGF binding protein & M35410 & & $1887.2( \pm 8255.8)$ & \\
\hline Zinc finger protein (ZNF76) & DNA binding protein & M91592 & & $17.9( \pm 52.5)$ & \\
\hline p38 gamma MAP kinase & Cell signaling & U66243 & & $35.0( \pm 53.6)$ & \\
\hline Pescadillo & Cell cycle regulation & U78310 & & $39.5( \pm 45.4)$ & \\
\hline HPV16 E1 protein bind protein & DNA replication & U96131 & & $30.9( \pm 50.6)$ & \\
\hline Clone C-2k, cdc2-related & Serine/threonine kinase & X80230 & & $12.6( \pm 14.2)$ & \\
\hline CLPP & Protease & Z50853 & & $23.4( \pm 38.3)$ & \\
\hline \multicolumn{6}{|l|}{ Underexpressed genes } \\
\hline Gravin & Kinase scaffold protein & AB003476 & $0.039( \pm 0.064)$ & $0.031( \pm 0.118)$ & $0.049( \pm 0.114)$ \\
\hline Mitochondrial matrix protein P1 & $\begin{array}{l}\text { Chaperone, posttranslational } \\
\text { activity }\end{array}$ & M22382 & $0.004( \pm 0.009)$ & $0.004( \pm 0.018)$ & $0.008( \pm 0.012)$ \\
\hline Putative tumor suppressor ST13 & Tumor suppressor & U17714 & $0.060( \pm 0.141)$ & $0.046( \pm 0.122)$ & $0.057( \pm 0.065)$ \\
\hline Transforming growth factor beta-2 & $\begin{array}{l}\text { Growth factor, cell cycle } \\
\text { regulation }\end{array}$ & M19154 & $0.076( \pm 0.169)$ & $0.140( \pm 0.232)$ & $0.037( \pm 0.122)$ \\
\hline $\begin{array}{l}\text { Cell adhesion protein receptor } \\
\text { alpha subunit (vitronectin) }\end{array}$ & Cellular adhesion & M14648 & $0.050( \pm 0.090)$ & $0.021( \pm 0.025)$ & $0.075( \pm 0.142)$ \\
\hline $\begin{array}{l}\text { Kruppel-associated box (KRAB), } \\
\text { clone BRc1744 }\end{array}$ & $\begin{array}{l}\text { Zinc finger domain, } \\
\text { transcriptional suppressor }\end{array}$ & M67509 & $0.039( \pm 0.033)$ & $0.030( \pm 0.050)$ & $0.060( \pm 0.136)$ \\
\hline Inhibitor of apoptosis protein 2 & Apoptotic suppressor & U45879 & $0.093( \pm 0.095)$ & $0.049( \pm 0.034)$ & $0.072( \pm 0.040)$ \\
\hline Syntaxin 7 & Intracellular vesicle trafficking & U77942 & $0.132( \pm 0.132)$ & $0.010( \pm 0.151)$ & $0.112( \pm 0.237)$ \\
\hline $\begin{array}{l}\text { CL100 mRNA for protein tyrosine } \\
\text { phosphatase }\end{array}$ & $\begin{array}{l}\text { MAPK phosphatase homolog, } \\
\text { protein dephosphorylation }\end{array}$ & X68277 & $0.063( \pm 0.106)$ & $0.080( \pm 0.215)$ & $0.117( \pm 0.248)$ \\
\hline Nucleoporin-like protein & Nucleocytoplasmic transport & X89478 & $0.127( \pm 0.156)$ & $0.115( \pm 0.158)$ & $0.122( \pm 0.115)$ \\
\hline Garp & $\begin{array}{l}\text { Protein-protein interaction, } \\
\text { signal transduction }\end{array}$ & Z24680 & $0.111( \pm 0.106)$ & $0.117( \pm 0.211)$ & $0.086( \pm 0.153)$ \\
\hline Pig7 (PIG7) & p53 target & AF010312 & & $0.092( \pm 0.210)$ & \\
\hline Protocadherin 68 (PCH68) & Cell adhesion & AF029343 & & $0.061( \pm 0.116)$ & \\
\hline Ras-related GTP-binding protein & Ras signal transduction & D78132 & & $0.058( \pm 0.097)$ & \\
\hline Protein phosphatase $2 A$ B56 $\varepsilon$ & Protein dephosphorylation & L76703 & & $0.127( \pm 0.195)$ & \\
\hline Ras-related protein (Krev-1) & Tumor suppressor & M22995 & & $0.015( \pm 0.025)$ & \\
\hline Nidogen & Basement membrane component & M30269 & & $0.121( \pm 0.220)$ & \\
\hline $\begin{array}{l}\text { Mutated in multiple advanced } \\
\text { cancers (MMAC) protein }\end{array}$ & Tumor suppressor & U92436 & & $0.037( \pm 0.128)$ & \\
\hline Novel DNA binding protein & Transcriptional regulation & X63071 & & $0.062( \pm 0.079)$ & \\
\hline Translin & Consensus sequence binding & X78627 & & $0.092( \pm 0.075)$ & \\
\hline mRNA for hevin-like protein & Extracellular matrix, cell adhesion & X86693 & & $0.004( \pm 0.098)$ & \\
\hline Caveolin & $\begin{array}{l}\text { Caveolae structural protein, } \\
\text { candidate tumor suppressor }\end{array}$ & Z18951 & & $0.031( \pm 0.080)$ & \\
\hline
\end{tabular}




\section{Discussion}

Dr Bryan Meyers (St Louis, Mo). Those are very elegant experiments and certainly a good step in the right direction with your preliminary work. I would ask you to discuss a little bit about the findings between 2 different clusters, cluster A being the tumors that were $\mathrm{T} 2$ and cluster $\mathrm{B}$, the tumors that were $\mathrm{T} 1$. One of the challenges with a small number of tumors like this, particularly when they are heterogenous, is that you are drawing some conclusions based on your molecular findings, but there are some other macroscopic findings that are also very associated with the tendency toward lymph node metastases.

Dr Hoang. Thank you for your comments. For clarification, cluster A was not comprised solely of T1 tumors nor was cluster $\mathrm{B}$ comprised solely of $\mathrm{T} 2$ tumors. The hierarchical clustering was based on a subset of genes that differentiated between tumor specimens by graded lymph node tumor burden. The resulting segregation of specimens into separate groups was therefore determined by nodal status. To ensure that this was the case, we examined the distribution of specimens according to other physical and molecular characteristics, including $\mathrm{T}$ status. There were no statistically significant associations, except for nodal status.

Dr Thomas A. D'Amico (Durham, NC). Dr Hoang, that was a wonderful presentation. I admire your work, and you and your colleagues should be congratulated. I wonder if you could discuss why you chose the presence of lymph node micrometastasis as the parameter to distinguish prognostic potential among stage I patients. There are other molecular markers, antigens, proteins, or gene mutations that would have given you a wider scope of tumors to choose from to use this 75-gene discriminant analysis to look at subgroups. Limiting yourself to whether or not a micrometastasis is present maybe wouldn't give you the same latitude. Could you discuss why you chose those subgroups?

Dr Hoang. Thank you for your very insightful question. A main focus of our lab is centered on mechanisms of nodal metastasis in NSCLC. Because micrometastases represent an early form of tumor dissemination, a better understanding of their biology may lead to new insights into underlying mechanisms. This specific interest led us to select tumors with nodal micrometastases for comparison against a true negative, that is, no nodal metastases (determined by H\&E and by our CEA QRT-PCR assay) versus a true positive, that is, overt nodal metastasis (advanced-stage tumors).

Dr Larry R. Kaiser (Philadelphia, Pa). Your 2400-gene array is a fairly small array. Was this somehow selected prior to using it?

Dr Hoang. This 2400-gene cDNA microarray was a commercial resource readily available to our laboratory. The 2400 genes spotted on the microarray represent a broad cross section of gene functional categories (eg, transcription factors, cell regulatory factors, cell signaling, cell adhesion, and so on), making it well suited for the broad gene profiling approach we used. Thus, there was no predetermined selection process.

Dr Kaiser. And most genomics data is not particularly useful unless it is validated externally. Did you attempt to validate this externally, for instance, with the data from Beer or from Bhatta- charjee, which was the paper from the Proceedings of the National Academy of Sciences?

Dr Hoang. That is an excellent question and important point you raise about microarray studies in general. With respect to your specific question about direct comparison of our data to the public lung cancer databases at Michigan (Beer and colleagues) and Harvard (Bhattacharjee and colleagues), we have not done that. There are significant technical reasons for not doing so that encompass differences in: (1) microarray platform (oligonucleotide vs CDNA), in number of overlapping genes present on each array, (2) specific types of samples being compared (whole tissue vs cells), (3) the reference sample (pooled tissue, pooled cell lines, single samples, tumor vs normal in same patient, etc), (4) normalization protocol, and (5) lack of consensus on a uniform approach to compare data across different studies. Thus, we are not sure of what approach would be taken or how valid it would be to attempt such a direct comparison. A crude method could consist of qualitative comparisons of genes reported as overexpressed or underexpressed.

Dr Kaiser. Another thing is that the statistical validation of any of these is particularly important, and we didn't hear much in the way of any statistical validation of any of these results. For instance, you had osteopontin as 90 -fold up-regulated. Was that just due to 1 sample, was it a low expressor, what was the $P$ value? There was some of the data that was a little bit hard to believe in terms of how much some of the gene expression was up-regulated.

Dr Hoang. Again, you bring up another important point about microarray data analysis. This is a rapidly evolving field with a multitude of statistical approaches, all of which have certain advantages and disadvantages. Currently there is no consensus on what the best approach is or if there should be a uniform approach taken. The $\mathrm{K}$ groups analysis we used refers to a family of data-filtering algorithms (part of our array analysis software); the specific test we performed to identify our discriminatory 75-gene subset is the separate groups, $\mathrm{K}$ groups test. This selection algorithm relies on a combination of rank-ordering tests with a Pearson correlation coefficient. The end result of applying this algorithm is the identification of genes with maximal variation between defined groups ( 3 in this case) that could be used to classify samples.

Depending on a number of technical factors (such as microarray platform, normalization algorithm, and type of comparison between experimental vs reference samples), a relatively large range of expression values could result. With respect to osteopontin, all 15 of our tumor specimens showed elevated expression with a range of about 6 -fold to 260 -fold. We did not report a $P$ value because our gene selection process relied on a correlation-based statistic.

Dr Kaiser. I think it is safe to say it is very interesting, but without some external validation, we have to be very careful about looking at genomics data.

Dr Hoang. We agree with your cautionary stance, overall. To address this concern, we used real-time PCR (the most common validation technique in current usage) to externally validate our microarray data for certain genes of interest. Overall, the 2 independent methods showed qualitative agreement. 